\title{
Ross procedure with a tissue-engineered heart valve in complex congenital aortic valve disease
}

\author{
Davide Gabbieri, MD, ${ }^{a}$ Pascal M. Dohmen, MD, PhD, a Jörg Linneweber, MD, ${ }^{a}$ Alexander Lembcke, MD, \\ Jan P. Braun, $\mathrm{MD}^{\mathrm{c}}$ and Wolfgang Konertz, MD, PhD, ${ }^{\mathrm{a}}$ Berlin, Germany
}

T he Ross procedure achieved an established position in the treatment of congenital aortic valve disease. ${ }^{1}$ However, right ventricular outflow tract $(\mathrm{RVOT})$ reconstruction still limits this procedure. We describe a patient with recurrent aortic valve stenosis after repeated surgical and interventional procedures. The Ross operation was performed, and the RVOT was reconstructed using a tissue-engineered (TE) heart valve.

\section{Clinical Summary}

A 23-year-old woman with congenital bicuspid aortic valve stenosis was referred to our department for recurrence of left ventricular-aortic pressure gradient after multiple surgical and interventional procedures at other hospitals. Chronologically, the patient underwent closure of the patent ductus arteriosus at birth, resection of a subaortic membrane and open valvotomy 5 years later, closure of iatrogenic ventricular septal defect during the next year, and new open valvotomy with closure of the residual ventricular septal defect at the age of 14 years. The following year a percutaneous balloon aortic valvotomy was performed. After the last procedure, the medical history was unremarkable until the patient started to have palpitations, evening asthenia, and recurrent incipient syncopes at 21 years of age. Paroxysmal supraventricular tachyarrhythmia caused by atrial flutter was demonstrated by 24-hour electrocardiography. Transthoracic echocardiography (TTE) demonstrated a maximal left ventricular-aortic pressure gradient of $87 \mathrm{~mm} \mathrm{Hg}$, an aortic valve orifice area of $0.7 \mathrm{~cm}^{2}$, and normal ejection fraction with mild concentric hypertrophy of the left ventricle. The interventional ablation of atrial flutter was performed before surgery to prevent postoperative recurrent supraventricular tachyarrhythmia. Granting the request of the patient to avoid any anticoagulants, we proposed to implant a TE heart valve during the Ross procedure. Informed consent was obtained. Construction of a TE heart valve was previously exhaustively reported. ${ }^{2}$ Briefly, endothelial cells were harvested, isolated, and cultured. One week before implantation, a 25-mm cryopreserved pulmonary allograft was decellularized and seeded by a sedimentation technique. The operation was performed with normothermic cardiopulmonary bypass using warm-blood cardioplegia. The autograft was implanted

\footnotetext{
From the Departments of Cardiovascular Surgery, ${ }^{\text {a Radiology, }}{ }^{\mathrm{b}}$ and Anesthesiology, ${ }^{\mathrm{c}}$ Charité Hospital, Medical University Berlin, Germany,

Received for publication Dec 6, 2006; accepted for publication Dec 12, 2006.

Address for reprints: Davide Gabbieri, MD, Department of Cardiovascular Surgery, Charité Hospital, Medicine University Berlin, Charitéplatz 1, D-10117 Berlin, Germany (E-mail: dgabbieri@yahoo.it).

J Thorac Cardiovasc Surg 2007;133:1088-9

$0022-5223 / \$ 32.00$

Copyright $\odot 2007$ by The American Association for Thoracic Surgery doi:10.1016/j.jtcvs.2006.12.023
}

using the root replacement technique, and the reconstruction of the RVOT was performed with the TE heart valve in a no-touch technique. The postoperative course was uneventful. The patient was discharged with instructions to take only $100 \mathrm{mg}$ of acetylsalicylic acid daily. Follow-up was performed by TTE, magnetic resonance imaging, and multislice computed tomography angiography, according to a protocol previously published. ${ }^{2}$ Thirty-six months after the operation, the patient is in New York Heart Association class I without any restrictions of her activities. During follow-up, TTE showed no regurgitation and minimal mean pressure gradients in both valves (Figure 1). These findings were supported by magnetic resonance imaging, which showed stable aortic and pulmonary pressure gradients, and left ventricular mass and volume reduction. The multislice computed tomography demonstrated no calcifications on both heart valves and showed smoothly moving leaflets without any retraction (Figure 2).

\section{Discussion}

The Ross procedure is widely used for treating aortic valve disease in children because of the growth potential of the pulmonary autograft, physiologic hemodynamic properties, negligible prevalence of infection, and absence of anticoagulation. ${ }^{1}$ The reconstruction of the RVOT has been generally performed using a pulmonary allograft. However, allografts represent nonviable structures and lack the ability to grow, repair, or remodel. Furthermore, they are subject to calcification and structural degeneration, mainly because of specific humoral and cellular immunologic response against type I and II histocompatibility antigens. ${ }^{3} \mathrm{Al}-$ though the underlying pathophysiologic mechanism is not completely known, other factors could be involved, such as a nonimmunologic-mediated adventitial fibrotic inflammatory reaction causing extrinsic compression of the conduit and an early postoperative stretching and lengthening of the homograft causing release of tissue factors responsible for an unspecific inflammatory reaction. ${ }^{4}$ The TE heart valves could overcome these limitations. Decellularization significantly reduces the tissue antigenicity without interfering with extracellular matrix integrity, which could enhance long-term durability. ${ }^{3}$ Excellent hemodynamic performance of the TE heart valve at 3 years, without any signs of tissue

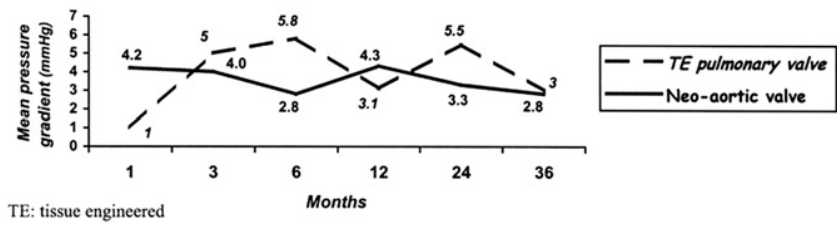

Figure 1. Echocardiographic evaluation of aortic and pulmonary valve mean pressure gradients. $T E$, tissue engineered. 


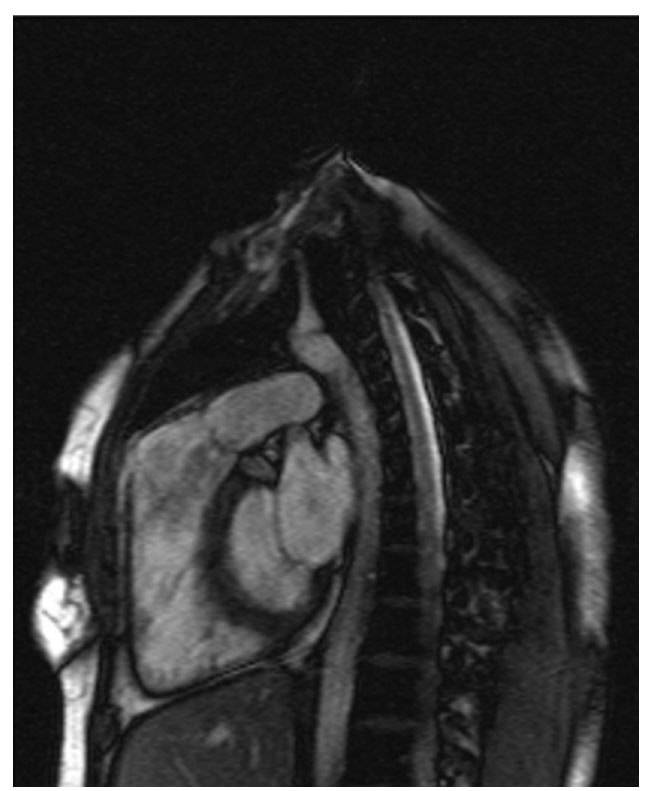

Figure 2. Multislice computed tomography: absence of calcification and tissue degeneration with smooth pliable valve leaflets of the TE heart valve after 3 years. $T E$, tissue engineered. degeneration, was shown. The process of endothelial cells seeding recreates a physiologic barrier that could reduce the procoagulatory activity of bare matrix components exposed to the blood. It is noteworthy that the potential for remodeling, regeneration, and growth of a decellularized allograft was proved in the juvenile sheep model. ${ }^{5}$

TE heart valves may represent an excellent option to reconstruct the RVOT during the Ross operation. However, long-term follow-up is needed to establish the superiority of these valves.

\section{References}

1. Al-Halees Z, Pieters F, Qadoura F, Shahid M, Al-Amri M, Al-Fadley F. The Ross procedure is the procedure of choice for congenital aortic valve disease. J Thorac Cardiovasc Surg. 2002;123:437-42.

2. Dohmen PM, Lembcke A, Hotz H, Kivelitz D, Konertz WF. Ross operation with a tissue engineered heart valve. Ann Thorac Surg. 2002;74:1438-42.

3. da Costa FD, Dohmen PM, Duarte D, von Glenn C, Lopes SV, Filho $\mathrm{HH}$, et al. Immunological and echocardiographic evaluation of decellularized versus cryopreserved allografts during the Ross operation. Eur J Cardiothorac Surg. 2005;27:572-8.

4. Zehr KJ, Yagubyan M, Connolly HM, Nelson SM, Schaff HV. Aortic root replacement with a novel decellularized cryopreserved aortic homograft: postoperative immunoreactivity and early results. $J$ Thorac Cardiovasc Surg. 2005;130:1010-5.

5. Dohmen PM, da Costa F, Holinski S, Lopes SV, Yoshi S, Reichert LH, et al. Is there a possibility for a glutaraldehyde-free porcine heart valve to grow? Eur Surg Res. 2006;38:54-61 